\title{
POLITICAL OPPOSITION AS A SUBJECT OF ELECTORAL PROCESS: PARTICIPATION FACTORS, TYPES ${ }^{1}$
}

\author{
Elena V. Efanova \\ Volgograd State University, Volgograd, Russian Federation \\ Nikolay Yu. Veremeev \\ Belarus State Economic University, Minsk, Republic of Belarus
}

\begin{abstract}
It is established that the specifics of politological approach to studying the phenomenon of opposition consists in the fact that it focuses on the main attributive features of opposition as the carrier of protest, "alternative" interests, namely, on opposition's organization and its aspiration to acquire power. The connection of political participation and political opposition has a dual character. On the one hand, the political opposition acts as one of the institutes of participation, a sort of intermediary which gives citizens the opportunity to participate in political life of the country. On the other hand, the opposition is one of the group agents of participation. The main channel of acquisition of the political capital for oppositional subjects is electoral process as the period of the greatest intensification of political life of the country, manifestation of the political orientations by citizens.

Thus, the authors base their study on the politological discourse in order to investigate the opposition as a political subject. They also reveal the determinants of political opposition's participation in the electoral process (character of a political regime, a sociocultural context, a condition of the competitive environment, parameters of selfidentification of political subjects. It is proved that subjectivity of political opposition within the electoral process reveals in the formation of consolidated "negative consensus" in relation to the power for the purpose of mobilizing the protest moods of population. When forming a uniform electoral strategy of actions, the opposition uses information opportunities for the purpose of articulating the "new" agenda and organizing different street protests.

E.V. Efanova has designated approaches to the operationalization of the phenomenon of opposition, systematized the types of political opposition. N.Yu. Veremeev has defined characteristics of opposition as a subject of electoral process, revealed the factors of participation of political opposition in elections.

Key words: opposition, political opposition, political institute, political subject, power, electoral process, political participation.

Citation. Efanova E.V., Veremeev N.Yu. Political Opposition as a Subject of Electoral Process: Participation Factors, Types. Vestnik Volgogradskogo gosudarstvennogo universiteta. Seriya 4, Istoriya. Regionovedenie. Mezhdunarodnye otnosheniya [Science Journal of Volgograd State University. History. Area Studies. International Relations], 2017, vol. 22, no. 6, pp. 30-37. (in Russian). DOI: https://doi.org/10.15688/jvolsu4.2017.6.3
\end{abstract}

\section{ПОЛИТИЧЕСКАЯ ОППОЗИЦИЯ КАК СУБЪЕКТ ЭЛЕКТОРАЛЬНОГО ПРОЦЕССА: ФАКТОРЫ УЧАСТИЯ, ТИПЫ ${ }^{1}$}

\author{
Елена Владимировна Ефанова
}

Волгоградский государственный университет, г. Волгоград, Российская Федерация

\section{Николай Юрьевич Веремеев}

Белорусский государственный экономический университет, г. Минск, Республика Беларусь 
Аннотация. Установлено, что специфика политологического подхода к изучению феномена оппозиции заключается в том, что он делает акцент на основных атрибутивных характеристиках оппозиции как носителя протестных, «альтернативных» интересов, а именно на ее организованности и стремлении к обретению власти как средству их реализации. Связь политического участия и политической оппозиции носит двойственный характер. С одной стороны, политическая оппозиция выступает одним из институтов участия, неким посредником, благодаря которому граждане получают возможность участвовать в политической жизни страны, с другой - оппозиция является одним из групповых агентов участия. Основным каналом приобретения политического капитала для оппозиционных субъектов является электоральный процесс как период наибольшей интенсификации политической жизни страны, проявления гражданами своих политических ориентаций.

Таким образом, авторами статьи обозначен политологический дискурс к изучению оппозиции как субъекта политики и определены детерминанты участия политической оппозиции в электоральном процессе (характер политического режима, социокультурный контекст, состояние конкурентной среды, параметры самоидентификации субъектов политики). Доказано, что субъектность политической оппозиции в рамках электорального процесса проявляется в формировании консолидированного «негативного консенсуса» по отношению к власти с целью мобилизации протестных настроений населения. При формировании единой электоральной стратегии действий оппозиция использует информационные возможности с целью артикуляции «новой» повестки дня и организации различного рода уличных акций.

Е.В. Ефанова обозначила подходы к операционализации феномена «оппозиция», систематизировала типы политической оппозиции. Н.Ю. Веремеев определил характеристики оппозиции как субъекта электорального процесса, раскрыл факторы участия политической оппозиции в выборах.

Ключевые слова: оппозиция, политическая оппозиция, политический институт, субъект политики, власть, электоральный процесс, политическое участие.

Цитирование. Ефанова Е. В., Веремеев Н. Ю. Политическая оппозиция как субъект электорального процесса: факторы участия, типы // Вестник Волгоградского государственного университета. Серия 4, История. Регионоведение. Международные отношения. - 2017. - Т. 22, № 6. - С. 30-37. - DOI: https://doi.org/ 10.15688/jvolsu4.2017.6.3

Операционализация категории оппозиции и применение того или иного подхода к ее изучению во многом зависят от исследовательского акцента на том или ином измерении явления оппозиции. А.Р. Курбанов выделяет три: деятельностное, субъектное и измерение, заключающееся в том, что оппозиция может рассматриваться как «особый тип взаимоотношений, взаимодействия политических субъектов» [4, с. 35].

Содержательная сторона деятельностного измерения раскрывается через понимание оппозиции в качестве одного из специфических видов деятельности, в том числе деятельности политической, выражающейся в совокупной массе действий агентов политического процесса, направленных против властной системы в целом либо ее отдельных компонентов. Выделение субъектного измерения связано с невозможностью рассмотрения деятельностного акта в отрыве от его носителя, в данном случае акцент в изучении смещается в сторону более глубокого рассмотрения носителя оппозиционной деятельности, контрагента власти. И, наконец, рассмотрение оппозиции как определенного типа взаимодействия политических субъектов позволяет акцентировать внимание на нормативных основаниях подобных взаимоотношений, ставя вопрос о процессе институционализации оппозиционной деятельности и становления института политической оппозиции.

Помимо существования различных измерений феномена оппозиции, стоит также говорить о трудностях дифференциации данного понятия с близкими ему по значению, но неравнозначными феноменами, которые возникают в силу лексического удобства его употребления для описания широкого круга явлений, сущность которых проявляется в категориях противоборства, конфликта, возникающих между различными социально-политическими субъектами. Наиболее близкими по отношению к понятию оппозиции явлениями выступают категории протеста, оппозиционности и оппозиционарности.

Политический протест, при том, что он может быть инициирован определенной политической силой, выступает явлением стихийным, что отличает его от оппозиции, являющейся организованным началом. У протестной массы, ясно осознающей, против чего она 


\section{ПОЛИТИЧЕСКИЕ НАУКИ И РЕГИОНОВЕДЕНИЕ}

действует, практически всегда отсутствует понимание того, за что она выступает, у нее нет позитивной программы действий. Протест реактивен, его основной целью является устранение спровоцировавших его внешних факторов, в то время как оппозиция не только противостоит тем или иным «возмущающим» ситуациям, но и вырабатывает альтернативные варианты политических решений, проекты реализации власти и стремится получить возможность для их осуществления. Понятие оппозиционности выступает категорией, включающей в себя комплекс социально-психологических феноменов, предшествующих и способствующих возникновению субъектов оппозиции. В свою очередь, категория оппозиционарности проявляется в «принятой системе ценностей, конструктивно-критической ориентации в поведении и деятельности субъектов политики, оппозиционных к официальной политике и практике» $[8$, с. 17].

Также необходимо разграничивать политическую оппозицию и группы интересов. Согласно А. Бентли, группа представляет собой «объединение граждан, рассматриваемых не как абстрактная физическая единица общества, а как массовая деятельность» [11], причем каждая группа имеет свои определенные интересы. Современное понимание групп интересов, сложившееся в политологической литературе, укладывается в дефиницию Г.В. Голосова, определяющего заинтересованные группы как «группы лиц, стремящихся воздействовать на процесс принятия решений по тем или иным отдельным вопросам» $[2$, c. 132]. Руководствуясь данным определением, можно отметить главное отличие групп интересов от политической оппозиции: при том что фактически и те, и другие представляют собой одну из форм группового участия в политике и ставят своей задачей оказание влияния на процесс управления в государстве, заинтересованные группы, тем не менее, не стремятся к обретению власти как средству ее достижения, в то время как для оппозиции это основная цель. Между тем, как отмечает Г.А. Гаврилов, оппозиционные партии часто опираются на группы интересов в плане политической и электоральной поддержки и выступают институциональными представителями этих групп в органах власти [1, с. 217].
Одной из главных атрибутивных характеристик политической оппозиции служит артикуляция интересов меньшинства, которые не представлены или недостаточно реализуются в проводимом политическом курсе, и, соответственно, защита этих интересов на всех властных уровнях посредством многообразных каналов влияния. Реализация этой задачи лежит в плоскости участия оппозиции в политике, принимающем различные формы.

Наиболее целесообразным и всесторонним представляется рассмотрение участия политической оппозиции в электоральном процессе, так как это позволяет избежать потери значительного сегмента, ведь взаимодействие организаций и кандидатов (в том числе и оппозиционных) с избирателями, электоратом, для того чтобы быть эффективным, не должно заканчиваться с оглашением итогов тех или иных выборов, воздействие организаций на электоральное поведение граждан должно быть непрерывным.

Электоральный процесс, в своей сущности, является процессом конкурентным, то есть предполагающим борьбу между политическими акторами за влияние на массы, определенные социальные слои и группы. Обеспечение повышения авторитета тех или иных лиц или организаций, получение того или иного государственного поста либо места в органе власти невозможно без изменения мнения и убеждений людей, привлечения на свою сторону электората, только влияя на общественное мнение и на депутатов, можно побудить последних проголосовать за нужные поправки к закону. Именно эти элементы и составляют участие политической оппозиции в электоральном процессе.

Стоит отметить, что электоральный процесс неоднороден, динамичен и структурирован, в нем можно выделить объекты и субъекты, условия протекания. Объектами электорального процесса выступают социальные группы и создаваемые ими институты, институты гражданского общества и неорганизованные граждане, стремящиеся к тому, чтобы реализовать свои интересы, в целом - электорат. Вопрос с субъектами представляется более сложным. К примеру, к субъектам избирательного процесса действующее законодательство причисляет государственные и 
муниципальные органы (в том числе избирательные комиссии), контролирующие инстанции - органы прокуратуры, которые осуществляют надзор за соблюдением законодательства, и суды, разбирающие соответствующие нарушения, а также участников избирательного процесса, обладающих правом выдвижения и поддержки кандидатов (например, политические партии, общественные объединения, в том числе и оппозиционные) [10, с. 119]. Субъектами электорального процесса также являются власть, политические институты и многие институты гражданского общества, однако не все политические партии, организации и общественно-политические движения можно причислить к субъектам. Субъект не пассивный участник электорального процесса, он носитель активного, преобразующего начала, выражающегося в его способности влиять на электоральное поведение путем совершения различного рода акций, коммуницирования с объектом своей электоральной политики, а именно - с гражданами, избирателями, электоратом.

Политическая оппозиция потенциально является субъектом электорального процесca. В качестве субъекта электорального процесса как части процесса политического политическая оппозиция имеет определенные характеристики. Среди подобных характеристик можно выделить следующие: организованность, наличие определенных интересов, отсутствие властного ресурса (и, как следствие, отсутствие возможности применения «административных методов»), стремление к его обретению для реализации интересов (и, как следствие, наличие активной практической деятельности, способной оказывать воздействие на поведение значительной части избирателей). Наличие всех этих свойств позволяет идентифицировать ту или иную оппозиционную группу как субъект электорального процесса.

Оппозиционные субъекты проводят свою электоральную политику, под которой подразумевается совокупность ее различных стратегических и тактических действий, которые основываются на учете социально-экономических, политических и духовно-идеологических факторов; правовых норм и правил проведения избирательных кампаний; ценностных установок, политических ориентаций, предпочтений, интересов ее субъектов, их стратификации, принадлежности к определенной среде и социальной группе; менталитета и специфики электоральной культуры, образующих электоральное сознание, представляющее собой оценочное отношение избирателя к политике в целом. Стоит отметить, что стратегия и тактика, применяемые оппозиционными и властными субъектами в электоральном процессе, несколько разнятся. Главным образом эта разница проявляется в характере коммуникационного сообщения, исходящего от коммуникатора к электорату. Если в первом случае это акцентирование внимания на недостатках проводимой политики, критика - предложение альтернативной политики, презентация своей большей состоятельности в решении тех или иных проблем, то во втором - это констатация своих достижений, отсылки к неудачному прошлому и т. д.

Основной целью оппозиционных субъектов в ходе электорального процесса является создание непротиворечивого имиджа, который был бы привлекателен для электората. Правильное позиционирование оппозиционного актора предполагает создание образа политической организации, притягательного для групп, которые будут способны оказать ей поддержку в период избирательных кампаний. Такая самопрезентация должна формировать у потенциального электората образ стабильно развивающейся и обладающей большим потенциалом организации, весомой силы, к которой уважительно относятся другие субъекты политической борьбы. Данная задача достигается в ходе реализации целого арсенала средств и методов, к числу которых можно отнести следующие: встречи с гражданами, потенциальным электоратом; инициирование общественных дискуссий по общезначимым вопросам; организация митингов и демонстраций; выдвижение альтернативных программ решения проблем, которые освещаются в СМИ; это также воздействие на властные структуры посредством института лоббирования для продвижения интересов организации и той социальной базы, которая за ней стоит.

Формы участия политической оппозиции в электоральном процессе зависят как от 
объективных, так и субъективных факторов. К числу объективных факторов стоит отнести социокультурный контекст, особенности политического сознания, традиций общества, в котором функционирует оппозиция, расстановку различных сил и характер конкуренции, форму правления и характер сложившегося политического режима, включая особенности институционализации участия в процессах планирования и принятия решений, а также от конкретной сложившейся ситуации. Внешняя среда электорального процесса, и прежде всего характер политического режима, который задает определенные институциональные гарантии, во многом и определяет уровни политических возможностей оппозиции, обусловливая и субъективные факторы выбора форм электорального участия, важнейшим из которых является тип политической оппозиции. В конечном итоге именно оппозиционная организация, принадлежащая к определенному типу, определяет стратегию и тактику своей деятельности. Таким образом, можно сказать, что между типом оппозиции и формой ее участия в политике, и в частности в электоральном процессе, существует прямая связь: тип оппозиции определяет формы ее участия в политике, в свою очередь, форма участия и средства, используемые той или иной оппозиционной организацией, позволяют в реальной политической практике идентифицировать ее с определенным типом. Исходя из этого, одной из важных задач становится определение типов политической оппозиции.

Основным критерием выделения типов политической оппозиции в западной политической науке является «соответствие целей оппозиции основным принципам конституционного строя и, как следствие, формы и средства политического участия» [6, с. 37]. В соответствие с данным принципом политическая оппозиция в западной политологической традиции подразделяется на два основных типа - внесистемную и системную.

Субъектами первого типа выступают прежде всего радикальные партии и организации, «характеристики сознания» которых не принимают систему социально-политических ценностей правящих групп и направление реализуемого в соответствии с ними политического курса. Вследствие чего при- оритет в деятельности оппозиционных субъектов данного типа отдается прежде всего неконвенциональным формам поведения, включая участие в несанкционированных акциях «прямого действия»-митингах, демонстрациях с возможным применение насильственных методов. Отчасти это вызвано программными установками самих оппозиционных организаций, не желающих добиваться власти посредством каналов, предоставляемых политической системой в силу того, что эти организации отвергают их. С другой стороны, этому способствуют и инсталлируемые властью различные препятствия на пути к участию подобных организаций в избирательном процессе. Внесистемная оппозиция зачастую использует электоральный процесс для делегитимации правящей власти и дестабилизации политической обстановки, для чего и применяют нелегальные методы борьбы [5, с. 47].

В отличие же от представителей внесистемной оппозиции, оппозиционные партии и организации, идентифицируемые как системные, признают оптимальность существующего социально-политического порядка, неизменность политико-институциональной системы государства, но между тем не приемлют правительственного курса в плане используемых им целей и средств для достижения общих стратегических целей. В рамках системной стратегии основными формами деятельности, используемыми оппозиционными акторами, выступают участие в парламентской деятельности, различных комитетах и контрольно-ревизионных органах, так как именно подобные действия оказываются наиболее эффективным способом влияния на формирование и реализацию политических решений, а также контроля их исполнения.

Несмотря на то, что разделение политической оппозиции на два основных сегмента системную и внесистемную - является традиционным для политической науки, существует и ряд исследователей, выделяющих дополнительный тип. В частности, С.Ф. Черняховский считает, что внесистемную оппозицию следует подразделять на «собственно “внесистемную”, при которой оппозиция образует некую автономную систему, способную существовать наряду с властной, и “антисистем- 
ную”, когда ее оформление в систему означает “уничтожение" противостоящей властной системы» [9, с. 29]. Внесистемная оппозиция представлена прежде всего теми оппозиционными организациями, которым в ходе избирательного процесса не удалось попасть в парламент страны, однако они не подвергают сомнению данный канал как инструмент, посредством которого можно участвовать во власти либо ее завоевать и обращают свои усилия на то, чтобы на последующих выбоpax решить задачу войти во власть. В соответствии с этим организации данного типа используют легальные формы участия в политике: санкционированные митинги, критика властей, инициирование публичных дискуссий в СМИ и научном сообществе, на которых бы обсуждались альтернативные варианты реализации политического курса, лоббирование своих интересов.

А.П. Цыганков называет три типа оппозиции: лояльную, умеренную и нетерпимую. В основу данного деления он закладывает «степень терпимости политической оппозиции по отношению к действиям правительства» [7, c. 98]. При этом он акцентирует внимание на собственно взаимодействии режима и оппозиции и последствиях для последнего оппозиционной деятельности.

Проанализировав все имеющиеся подходы к типологизации политической оппозиции, Е.С. Дерябина выделяет два больших направления, рамки которых и задают тот или иной контекст классификации: аксеологический и онтологический. В русле аксеологического подхода оппозиция делится на лояльную, конструктивную, непримиримую (радикальную), умеренную и т. д. [3, с. 39]. В рамках данного направления акцент делается на деятельностном проявлении оппозиционности различных агентов по отношению к властным субъектам, при этом в фокус рассмотрения не попадает система ценностей данных агентов, что делает невозможным точное определение степени этой оппозиционности.

В свою очередь, в рамках онтологического подхода в основу классификации закладывается в первую очередь вопрос соответствия стратегических целей оппозиционных агентов институциональным принципам, закрепленным политической системой, в которой они функционируют. Исходя из этого подхода, можно сказать, что политические агенты, не принимающие «правил игры», заданных существующим политическим режимом, и не имеющие возможности обретения власти, причисляются к внесистемной оппозиции; в свою очередь, оппозиционные агенты, добивающиеся своих целей в рамках возможностей, предложенных системой, причисляются к системным [3, с. 39].

Можно сказать, что каждая из приведенных типологий отражает тот или иной нюанс в структуре, положении и деятельности политической оппозиции, делает акценты на тех или иных формах проявления оппозиционности. Лишь взятые в совокупности, они могут претендовать на адекватное отражение феномена, который называется политической оппозицией. Ведь зачастую оппозиционные организации, идентифицируемые как системные, прибегают к неконвенциональным формам участия, в то время как внесистемные или антисистемные могут действовать в рамках легального поля. На выбор оппозицией форм политического участия значительное влияние оказывает конкретная политическая ситуация, имеющая тенденцию к изменению конфигурации. Однако несомненно то, что конвенциональные формы участия, и главным образом участие в электоральном процессе, являются превалирующими в оппозиционной деятельности.

Таким образом, электоральный процесс, как период наибольшей интенсификации политической жизни страны, проявления гражданами своих политических ориентаций, выступает одним из наиболее оптимальных полей оппозиционной деятельности, каналом достижения политических ресурсов, необходимых для реализации своих альтернативных интересов. Особенности протекания электорального процесса во многом зависят от объективных и субъективных факторов, включающих характер политического режима и задаваемых им институциональных возможностей, социокультурный контекст, характер конкуренции, параметры самоидентификации его основных субъектов, которые в конечном итоге обусловливают и формы участия в нем оппозиционных агентов. 


\section{ПРИМЕЧАНИЕ}

${ }^{1}$ Исследование выполнено при финансовой поддержке РФФИ, проект «Оппозиционные молодежные общественно-политические объединения в политическом пространстве России: функциональная специфика, региональные особенности» № 16-33-01026.

\section{СПИСОК ЛИТЕРАТУРЫ}

1. Гаврилов, Г. А. Феномен политической оппозиции: теоретический аспект / Г. А. Гаврилов // Научный ежегодник Института философии и права УрО РАН. - 2002. - № 3. - С. 217-228.

2. Голосов, Г. В. Сравнительная политология : учеб. пособие / Г. В. Голосов. - СПб. : Изд-во Европейского ун-та, 2001. - 368 с.

3. Дерябина, Е. С. Политическая оппозиция в переходный период отечественной истории (19851993 гг.) : дис. ... канд. ист. наук / Дерябина Екатерина Семеновна. - Пермь, 1998. - 259 с.

4. Курбанов, А. Р. Оппозиция как субъект политического процесса: на примере России : дис. ... канд. полит. наук / Курбанов Артемий Рустямович. М., 2009. -185 c.

5. Медведев, Н. П. Несистемная оппозиция в политическом пространстве современной России / Н. П. Медведев, А. В. Борисенко // Научные ведомости БелГУ. - 2008. - № 4. - С. 45-54.

6. Поршаков, С. А. Политическая оппозиция в странах запада (Некоторые закономерности и особенности функционирования) / С. А. Поршаков // МЭ и МО. - 1998. - № 3. - С. 35-48.

7. Цыганков, А. П. Современные политические режимы: структура, типология, динамика / А. П. Цыганков. - М. : Интерпракс, 1995. - 296 с.

8. Чернокозова, М. О. Феномен оппозиционарности в демократизирующемся российском обществе / М. О. Чернокозова. - М. : МГСУ, 2002. - 214 с.

9. Черняховский, С. Ф. Коммунистическая оппозиция в современной России: генезис, противоречивость, перспективы : автореф. дис. ... д-ра полит. наук / Черняховский Сергей Феликсович. - М., $2007-48$ c.

10. Шахназарян, Т. Г. Субъектный состав электоральной политики: теоретико-правовой аспект / Т. Г. Шахназарян // Вектор науки ТГУ. - 2011. № 1 (4).-C. 119-132.

11. Bentley, A. The Process of Government: A Study of Social Pressures / A. Bentley. - Electronic text data. - Mode of access: http://downloads. pavroz.ru/files/Bentlyprocess.pdf (date of access: 05.06.2017). - Title from screen.

\section{REFERENCES}

1. Gavrilov G.A. Fenomen politicheskoy oppozitsii: teoreticheskiy aspekt [Phenomenon of Political Opposition: Theoretical Aspect]. Nauchnyy ezhegodnik Instituta filosofii i prava UrO RAN, 2002, no. 3, pp. 217-228.

2. Golosov G.V. Sravnitelnaya politologiya [Comparative Political Science]. Saint Petersburg, Izd-vo Evropeyskogo un-ta, 2001. 368 p.

3. Deryabina E.S. Politicheskaya oppozitsiya $v$ perekhodnyy period otechestvennoy istorii (19851993 gg.): dis. ... kand. ist. nauk [Political Opposition during the Transition Period of National History (19851993). Cand. hist. sci. diss.]. Perm, 1998. 259 p.

4. Kurbanov A.R. Oppozitsiya kak subyekt politicheskogo protsessa: na primere Rossii: dis. ... kand. polit. nauk [Opposition as a Subject of Political Process: the Case of Russia. Cand. polit. sci. diss.]. Moscow, 2009. 185 p.

5. Medvedev N.P., Borisenko A.V. Nesistemnaya oppozitsiya $\mathrm{V}$ politicheskom prostranstve sovremennoy Rossii [Non-System Opposition in Political Space of Modern Russia]. Nauchnye vedomosti BelGU, 2008, no. 4, pp. 45-54.

6. Porshakov S.A. Politicheskaya oppozitsiya v stranakh zapada (Nekotorye zakonomernosti i osobennosti funktsionirovaniya) [Political Opposition in the Countries of the West (Some Regularities and Features of Functioning)]. ME $i M O$, 1998, no. 3, pp. 35-48.

7. Tsygankov A.P. Sovremennye politicheskie rezhimy: struktura, tipologiya, dinamika [Modern Political Regimes: Structure, Typology, Dynamics]. Moscow, Interpraks Publ., 1995. 296 p.

8. Chernokozova M.O. Fenomen oppozitsionarnosti $v$ demokratiziruyushchemsya rossiyskom obshchestve [Phenomenon of Opposition in the Democratized Russian Society]. Moscow, MGSU Publ., 2002. 214 p.

9. Chernyakhovskiy S.F. Kommunisticheskaya oppozitsiya $v$ sovremennoy Rossii: genezis, protivorechivost, perspektivy: avtoref. dis. ... polit. nauk [Communistic Opposition in Modern Russia: Genesis, Discrepancy, Prospects. Cand. polit. sci. diss.]. Moscow, 2007. 48 p.

10. Shakhnazaryan T.G. Subyektnyy sostav elektoralnoy politiki: teoretiko-pravovoy aspekt [Subject Structure of Electoral Policy: Theoretical and Legal Aspect]. Vektor nauki TGU, 2011, no. 1 (4), pp. 119-132.

11. Bentley A. The Process of Government: A Study of Social Pressures. URL: http://downloads. pavroz.ru/files/Bentlyprocess.pdf. (accessed June 5, 2017). 
Е.В. Ефанова, Н.Ю. Веремеев. Политическая оппозиция как субъект электорального процесса

\section{Information about the Authors}

Elena V. Efanova, Candidate of Sciences (Politics), Associate Professor, Department of International Relations, Political Science and Area Studies, Volgograd State University, Prosp. Universitetsky, 100, 400062 Volgograd, Russian Federation, efanova@volsu.ru, http://orcid.org/0000-0003-2019-1273

Nikolay Yu. Veremeev, Candidate of Sciences (Politics), Head of Department of Political Science, Belarus State Economic University, Prosp. Partizansky, 26, 220070 Minsk, Republic of Belarus, mr.veremeev@gmail.com, http://orcid.org/0000-0002-3526-5549

\section{Информация об авторах}

Елена Владимировна Ефанова, кандидат политических наук, доцент кафедры международных отношений, политологии и регионоведения, Волгоградский государственный университет, просп. Университетский, 100, 400062 г. Волгоград, Российская Федерация, efanova@volsu.ru, https://orcid.org/0000-0003-2019-1273

Николай Юрьевич Веремеев, кандидат политических наук, заведующий кафедрой политологии, Белорусский государственный экономический университет, просп. Партизанский, 26, 220070 г. Минск, Республика Беларусь, mr.veremeev@gmail.com, https://orcid.org/0000-0002-3526-5549 